\title{
A Little Knowledge Is A Dangerous Thing: Model Specification, Data History, and CDO (Mis)Pricing*
}

\author{
Dan $\operatorname{Luo}^{\dagger}$ \\ Dragon Yongjun Tang $\ddagger$ \\ Sarah Qian Wang ${ }^{\S}$
}

December 15, 2008

\begin{abstract}
The ongoing credit crisis is largely caused by the revaluation of collateralized debt obligations (CDOs). CDOs are one of the most successful innovations in financial history. In order to meet investor demand for credit products at different risk levels, CDO structurers pool credit instruments into collateral portfolio and tranching the portfolio cash flows into different seniority classes. This financial engineering process is proved to be flawed. Extreme default losses are severely underestimated by CDO evaluators. Simulating the frailty correlated default model of Duffie, Eckner, Horel, and Saita (2008), we show that CDO mis-pricing can be partly attributed to the limited availability of historical CDO data and, to a larger extent, model misspecification. This finding is supported by empirical evidence from historical CDO data. Our study addresses practical issues on financial innovations and provides underpinnings of the current financial crisis.
\end{abstract}

JEL Classification: G12; G13; E43; E44

Keywords: CDO; Model Specification; Data History; Default Correlation; Frailty

*We thank Wing Suen for useful comments.

†School of Economic and Finance, University of Hong Kong. Phone: (+852) 28578637. Email: luodan35@hku.hk

${ }^{\ddagger}$ School of Economic and Finance, University of Hong Kong. Phone: (+852) 22194321. Email: yjtang@hku.hk

${ }^{\S}$ School of Economic and Finance, University of Hong Kong. Phone: (+852) 28578637. Email: sarawang@hku.hk 


\title{
A Little Knowledge Is A Dangerous Thing: Model Specification, Data History, and CDO (Mis)Pricing
}

\begin{abstract}
The ongoing credit crisis is largely caused by the revaluation of collateralized debt obligations (CDOs). CDOs are one of the most successful innovations in financial history. In order to meet investor demand for credit products at different risk levels, CDO structurers pool credit instruments into collateral portfolio and tranching the portfolio cash flows into different seniority classes. This financial engineering process is proved to be flawed. Extreme default losses are severely underestimated by CDO evaluators. Simulating the frailty correlated default model of Duffie, Eckner, Horel, and Saita (2008), we show that CDO mis-pricing can be partly attributed to the limited availability of historical CDO data and, to a larger extent, model misspecification. This finding is supported by empirical evidence from historical CDO data. Our study addresses practical issues on financial innovations and provides underpinnings of the current financial crisis.
\end{abstract}

JEL Classification: G12; G13; E43; E44

Keywords: CDO; Model Specification; Data History; Default Correlation; Frailty 


\section{Introduction}

The ongoing 2007/2008 credit crisis has claimed unprecedented casualties. Investment banks almost disappeared in September 2008. ${ }^{1}$ Billions of dollars were written down from financial balance sheets. Hundreds of thousands of corporate employees are being laid off. At the center of this crisis is the previously little known financial innovation called collateralized debt obligations (CDOs). CDOs are one of the most widely issued structured finance instruments. The payoffs of CDOs depend on the performance of pools of collateral. The most significant feature of CDO, however, is that it allows its originator to issue a prioritized capital structure of derivative claims against the underlying collateral pool. Based on the prioritizing scheme, senior tranche CDO suffers only after the principal of the subordinate tranches has been exhausted, which in turn generally can gain higher credit ratings. Although boasting the most successful financial innovation in recent decades and growing exponentially until the burst of the crisis, CDOs turned out to be severely mispriced. ${ }^{2}$ This study examines the causes of CDO mispricing.

The innovative nature of CDOs makes it difficult to pin down the exact reasons for this valuation failure. On one hand, given the short history of the product and modeling difficulties, Duffie (2007) doubted anyone could have evaluated CDOs with comfortable accuracy. On the other hand, some regulators and media have rushed to cry fouls pointing to parties, such as underwriters and rating agencies, who brought CDOs to the marketplace. While it is possible that conflicts of interests could have played some role in underwriters and rating agencies misleading investors, "careful research is needed to distinguish the relative importance of the bad incentives view and the mispricing view" as these two views have distinctly different implications for regulation and risk management going forward (Allen (2008)).

Given the limitation of data availability and modeling techniques, large losses do not automatically imply risk management failures (Stulz (2008)). This argument is particularly relevant for the current setting of CDOs which are collateralized on pool of default-risky assets. Accurate valuation of CDOs requires modeling the joint distribution

\footnotetext{
${ }^{1}$ Among the top five Wall Street investment banks, one declared bankruptcy, two were acquired, and the other two converted into commercial banks.

${ }^{2}$ For instance, in May 2008, Merrill Lynch sold some CDOs to a Texas hedge fund at 22 cents on a dollar.
} 
of those assets, especially the default correlation. Defaults are rare events. Hence, default correlation is hard to measure. Furthermore, even single-obligor credit risk analysis proves to be difficult, there is little consensus on the best practices on portfolio credit risk modeling. In this paper, we examine the impact of data limitation and model uncertainty on portfolio credit risk evaluation and CDO mispricing. ${ }^{3}$

Traditional portfolio credit risk models such as Vasicek (1987) assume that default correlation is driven only by observable common factors. However, recent studies show that such approach significantly under-estimate the actual default correlation (Das, Duffie, Kapadia, and Saita (2007)). Based on this observation, Duffie, Eckner, Horel and Saita (DEHS, 2008) propose a frailty correlated default model, in which the latent "frailty" factor is unobservable and time-varying. The frailty approach is popular for modeling mortality rates in acturial science (see, e.g., Wang and Brown (1998)). Duffie, Eckner, Horel and Saita (2008) show that their model performs well in matching historical default patterns.

We first show, via simulations, that the DEHS frailty model indeed is a good modeling approach. It can accurately identify the true default process with or without actual frailty. After verify the DEHS model, we use it to conduct Markov Chain Monte Carlo (MCMC) analysis on the effect of data history and model uncertainty on portfolio credit risk valuation and $\mathrm{CDO}$ mispricing. Because defaults are rare and credit cycles take long time to materialize, we demonstrate that short data history, say, five years of month observations, will significantly underestimate the tail distribution of the credit portfolio and default correlation. Consequently, the most senior tranches of CDOs, which are often rated AAA, are actually much risker than model outcome based only on recent data. Subsequent realization of more default scenarios then triggers downward adjustments of those initially highly rated CDO tranches, as experienced in the unfolding of current crisis.

Short data history also implies that the sample realization will be unpredictable and unrepresentative. In other words, there will be too many defaults when the economy is doing poorly, but there will be too few defaults when the economy is doing well, just like the 2003-2007 period. We show that this random realization of data history can also significantly affect the accuracy of portfolio credit risk. The most senior tranche

\footnotetext{
${ }^{3}$ The issues on conflicts of interest and CDO security design are left for other research, e.g., Griffin and Tang (2008), Nicolo and Pelizzon (2008).
} 
of a CDO (such as the 30\%-100\% tranche of the popular credit index CDX.NA.IG) with AAA rating will essentially have zero default probability if evaluated in a good economy. However, the default probability can increase to $0.7 \%$, which is significant enough to bring down the rating to A.

The large scale of CDO rating failure is potentially consistent with our simulation finding. To verify this conjecture, we apply the frailty model to a real CDO structured by Lehman Brothers in March 2008. Our empirical analysis supports the simulation results that model specification and and data history are critical to accurate CDO valuation.

Our simulation exercises demonstrate an even more important role for model uncertainty. The basic construct of CDO is the diversification benefit of credit portfolio. This premise is fundamental for producing AAA tranches from lower rated collateral assets. Not until recently did we learn about the frailty factor and under-estimation of default correlation. If we ignore the frailty factor in the data generating process, portfolio credit risk will be severely underestimated even if long data history is available. Data availability helps little in attenuating the model uncertainty effect. Our finding indicates that no matter how long the market practices the CDO investment vehicle, our understanding of the pricing dynamics will prove little if we employ a mis-specified model.

We make three contributions to the literature. First, we provide the underpinning of CDO mispricing which largely caused the ongoing credit crisis. Rating agencies might not have done a good job evaluating CDOs, but their constraints on data availability and accurate modeling limited their capability to do better. Second, although model uncertainty is well studied in equity markets and portfolio allocation (e.g., Garlappi, Uppal, and Wang (2007)), we take it to the credit derivatives market and present its strong impact. Model error was probably the biggest single factor for the CDO valuation failure. Third, our study provides a good framework for analyzing financial innovations, which will surely continue and same issues will appear repeatedly. Therefore, our research sets up a guideline for future financial practice.

Our study is built upon Duffie, Eckner, Horel and Saita (2008). We add to existing studies in the following ways. While Longstaff and Rajan (2008) argue that historical CDO prices are well explained, Brennan, Hein, and Poon (2008) and Coval, Jurek, and Stafford (2008) show that substantial mispricing can arise in the CDO structuring process. Our finding of systematic mispricing due to limited data availability and model 
uncertainty provides a justification for above seemingly conflicting findings. Fender, Tarashev, and Zhu (2008) also show that CDO can be overvalued relative to equivalent corporate bonds. Eckner (2008), Feldhtter (2008) and Heitfield (2008) use MCMC for CDO pricing. Our study differs by the economic motivation. Finally, our paper makes similar points to the commentary paper by Coval, Jurek, and Stafford (2009).

The rest of this paper is organized as follows. Section 2 reviews the setting of our study and relevant literature in greater detail. Section 3 describes the latent frailty default model and our simulation method. Our main findings on the effects of data history, model uncertainty and their interaction are presented and discussed in Sections 4. We provide a case study using real CDO in Section 5. Section 6 concludes the paper.

\section{CDO Market and Literature Review}

The CDO market experienced explosive growth in recent years. Annual issuances of CDOs have grown from about $\$ 17$ billion in 1997 to above $\$ 500$ billion in 2006 and 2007. CDOs are a type of asset-backed securities (ABS $)^{4}$ Major asset types include corporate loans and bonds but other types include credit card debt and credit derivative contracts. Most CDOs have multiple tranches where parts of the tranches are sold to different investors. However, single-tranche CDOs ("bespoke" CDOs) are often structured specifically for a particular investor need.

Credit risk portfolio valuation is difficult due to non-normal distributions. Closedform solutions can only be obtained under strong assumptions. In practice, simulations are run to determine future portfolio value. All three major rating agencies (S\&P, Moody's, and Fitch) employ simulation approaches when rating CDOs. Two different approaches are often used to derive credit portfolio value from individual credit assets. The structural approach (or "copula" approach, used especially by S\&P) assumes asset value processes are correlated. Asset value is simulated sequentially with correlations imposed on each subsequent asset of assets already simulated. Credit portfolio value is determined after all assets are simulated. Repeating the simulation multiple times result in a distribution of the portfolio value. Probability of default is determined by the

\footnotetext{
${ }^{4} \mathrm{CDO}$ are distinguishable from traditional ABS in two aspects. First, CDO assets are held in a bankruptcy-remote special purpose vehicle with the CDO being its only purpose. Second, CDO structure and underlying assets are much more diverse than traditional ABS.
} 
tranching. An "idealized" mapping converts probability of default to a credit rating.

\subsection{Portfolio Credit Risk and CDO Valuation}

CDOs are constructed from underlying portfolio characterized by collateral credit quality, maturity and correlation. The cash flows are tranched into different classes. The credit quality of each class depends on the recovery rate as well as credit enhancements. The valuation of CDO, therefore, starts with and depends heavily on the accurate assessment of the credit risk of the underlying portfolio. With the derived probability distribution of default for a given CDO underlying portfolio, the ratings of tranches are determined by referring to the Scenario default rate (SDR) as employed by Standard \&Poor's in its CDO evaluator system.

As to the first and critical step of portfolio default probability estimating, various models could be used. As mentioned above, the classic Merton DD model could be modified(may be in various ways) to incorporate the default correlation in the asset portfolio. Based on the Merton (1974), Merton DD model regards the equity value as a call option on the firm's underlying value with the strike price set at the face value of debt. To get the model implied default probability, the firms' underlying value and its volatility et al are inferred from the firm's equity value. An iterative procedure is used for the value calculation. Then the Merton DD Probability is the normal cumulative density function of a Z-score depending on the above calculated variables. However, the accuracy of the model is restricted tightly by the underlying strong assumptions. Therefore the base Merton DD model for single firm default estimation is modified to improve the estimation accuracy which gives rise to various forms of following up structural models.

Eom, Helwege and Huang (2004) compare the structural models for corporate bonds spread from the empirical perspective. While the implied bond spreads from the Merton model tend to underestimate the spreads realized in the market, other structural models, however, seem to on average suffer from the overestimation problem. Moreover, given the generally over prediction, especially for the high leveraged firm, some structural models are even more likely to underestimate the relatively safety bonds at the same time. Then for the accurate consideration, an ideal structural model should be able to produce justified spread without bias. Andreou and Ghysels (2008) emphasize the effect 
of structural shifts to the credit risk structural model. Instead of fixing the structural model parameter at some points, they point out that it is necessary taking into account of the structural parameter variation. Failed to incorporate this effects may results in biased inferences based on the credit model. An optimal sequential quality control procedural with minimum detecting time for monitoring the structural breaks is suggested, which is extremely useful for monitoring the corporation stability in financial distress period. Moreover, with a good finite sample behavior as indicated in their simulation, the suggested procedure could be used for the quality control of the credit models.

Coval, Jurek, and Stafford (2008) explicit modified the Merton (1974) for the CDO underlying portfolio risk estimation. In their paper, a factor structure was added to the Merton(1974) structural model of debt. Under this setting, firm asset values are exposed to a common market factor, and therefore the default correlation are introduced. Other models, such as various reduced form models, are widely used in assessing portfolio risk as well. As many as the choice are, model uncertainty problem are widely accepted. This uncertainty problem undoubtedly will affect the CDO valuation accuracy.

\subsection{CDO Pricing and Rating}

To get a certain tranche rating, the default probability of this tranche must withstand that indicated by its SDR. The SDR for a target rating tranche can be determined by calculate the portfolio default rate by referring to the corresponding rated corporate bond, as well as making some adjustment according to the default experience. Note that the portfolio default rate in the SDR calculating is assumed to capture the likelihood of default for a target tranche rating, which is determined in such a way that the "probability of default in the portfolio exceeding this default rate is no greater than default probability of" corresponding corporate bonds with the same rating. Then the SDR can be got by adjusting the portfolio default rate with an adjustment factor for specific tranche raring, which will incorporate the eventual default experience of that asset class.

CDO pricing difficulty comes not only from Model uncertainty and Limited data history, as addressed apparently in this paper, but also from the local thinking which exacerbates the problem. Gennaiolio and Shleifer (2008) discuss the local thinking problem in detail, and present a nearly Bayesian Model of decision making. Following the 
work by Daniel Kahnman and Amos Tversky (1972, 1974, 1983, 2002), they suggest that decision makers, evaluating the probability based on the representativeness, are likely to be mislead and therefore make a mistake. The mistake comes from the fact that, generally, the representativeness is consisted of the more frequent and common evens, and moderate mistake is witnessed for the probability estimation. When there is a mismatch between the representative and frequency, however, for a local thinker with limited memory, the probabilities of the rare events tend to be severely underestimated. Inspiring by this logic, the rare extremely default probability, which is undoubtedly a rare event may severely underestimated by the local thinker.

\subsection{Frailty and Default Correlation}

Although agency conflicts may arise during the security design (Mehran and Stulz (2007), SEC (2008)), structured finance instruments, CDOs in particular, can be useful investment tools as long as the default correlation is low, as shown by DeMarzo (2005) and Leland (2007). However, default correlation is hard to measure and this part contributed mostly to the failure of CDO valuation (Brunnermeier (2008), BIS (2008), Crouhy, Jarrow, and Turnbull (2008), Hull (2008), Plosser (2008), S\&P (2008)). For such low occurrence events, Bayesian approach is particularly appealing (Kiefer (2008), McNeil and Wendin (2007), Glasserman and Li (2005), Loffler (2003)).

In a standard structural model, a firm is assumed to default when its terminal value of asset falls below the face value of debt. Merton (1974) is a good case in point. In many of these models, firm-specific distance to default has been used as the sole defaultprediction covariate. Nevertheless, as shown by Duffie and Lando (2001) undue precision of distance to default will result in filtering problems in default probability estimation.

Depart from the structural models of default, Duffie, Saita and Wang (2007) employs another modeling approach. The main difference between these two approach are the nature of the event that triggers default, as well as the model fitting with the empirical data. While the structural models identify default when distance to default falls below certain barrier, Duffie, Saita and Wang (2007)'s model assumes that defaults occur randomly at each small time period with a probability determined by not only the current distance to default, but also other covariates including firm's trailing stock return, interest rates and market-wide stock returns. 
For the structured finance instruments such as CDO, however, to assess the default and risk, it is necessary to consider both the firm specific default predictors, and more importantly, the default correlation among assets in the underlying pool. Bonfim (2008), Koopman, Kraussl, Lucas, and Monteiro (2008), Jimenez and Mencia (2008), Berd, Engle, and Voronov (2007) all stress the importance of not only the observable correlation, but also the unobservable correlation. Model uncertainty is also discussed by Cont (2006) and Rajna (2000).

A conventional portfolio-loss risk model assumes that default correlation comes only from the observable factors. Even with the benefit of these various of firm-specific and macroeconomic observable covariates, however, Das, Duffie, Kapadia, and Saita (2007) finds empirical evidence that defaults are more clustering than suggested by conventional models based merely on observable factors. With roughly the same data, Duffie, Eckner, Horel and Saita (2008) provides a new model for corporate default intensity with a time varying common latent factor, and in the presence of a firm specific unobservable covariate. They find that the prediction power of a general credit model will be increased dramatically by incorporating an common unobservable covariate. Compared with the traditional method, this model is especially good for the default clustering estimation. If the model parameters are tied to the maximum likelihood estimators, however, they showed that this model is still suffered from parameter uncertainty . To solve this problem, Bayesian approach has been used as a robustness check, and result in dramatic improvement in the tail default estimation.

Traditionally, CDO credit risk has been assessed through models including only observable covariates. Duffie, Eckner, Horel and Saita (2008), however, suggests a new dynamic frailty model with a common unobservable factor. Although compared with the traditional model, the dynamic frailty model avoids a significant downward omittedvariable bias, the estimation still suffers from parameter uncertainty. Limited data history further deteriorates the estimation accuracy. While Bayesian approach is employed to solve the parameter uncertainty, no research has been done for the effect of limited data history.

In the spirit of Duffie, Eckner, Horel and Saita (2008), we use dynamic frailty model as the benchmark model for portfolio loss estimating. To assess the data history effect, we further develop various scenarios for firm specific observable covariates. This can be achieved by controlling the data generating process. We would expect to see significant 
change in the default estimation, especially for the tails, by varying the hypothetical data scenarios. This finding has an important implication for assessing the credit risk of senior CDO, which confines its loss to tail default distribution of the underlying collaterals.

As to the CDO pricing, Coval, Jurek and Stafford (2008) find that CDO and many other structured finance instruments behave similar to the Economic Catastrophe Bonds which defaults only under extreme bad economic states. This feature indicates that the dramatically increased probability of default in bad economic states with severe default clustering actually is an extra source of risk for the high rated CDO tranches. CDO credit ratings provided by high prestige rating agency are in fact not reliable for their ignoring of economic states effects. To correct the pricing failure, in this paper, they further develop a state contingent frame work for CDO pricing. State contingent default probability is calculated based on the modified Merton(1974)'s model. By comparing the model implied premium with the actual market premium, they conclude by saying that CDO senior tranches are inaccurately priced, and relative senior tranche investors should have required higher risk premium than that indicated by the simple credit rating.

Coval, Jurek and Stafford (2009) examine the economics of the structured finance products as a whole, and attribute the current failure of the market to the special feature of the structured finance products. CDO has been taken as a representative example. Specifically, while rating agency has achieved dramatic success in creditworthiness assessment of single name securities, the minor model's failure of the rating agency tends to be greatly magnified for the structured finance products rating. This might accounts for some of the severely downward correction of the previous relatively high ratings. Recognized this negative feature of the structured finance, Bayesian approach, for example, has been applied in the model to fix the mistake called parameter uncertainty. The other dramatic feature of structured finance products, however, indicates that even with the most accurate model, rating agency cannot derive a reliable rating without considering the economic states, especially for the senior CDO tranche. As discussed in Coval, Jurek and Stafford (2008), the economic catastrophe feature makes the senior tranche investment extremely dangerous in bad economic states, and therefore this seeming $100 \%$ safety tranche should not have been assigned as AAA. Last but not least, it is worth to note that the low interest rate environment also facilitates the past vast popularity of structured finance products. Compared with the low risk free rate, the 
seemingly AAA guarantee and relatively higher promised spreads did attract investors around the world, even if they do not fully understand this complex financial derivative.

With the continuous refinements in the pricing model, problem arises again, nevertheless, when considering the limited data history. With the limited 25 years data in Duffie, Eckner, Horel and Saita (2008)'s paper, it seems not enough to tie down the model parameters. The model parameters may be sensitive to different data structure, which in turn may generate different default estimation.

In this paper, we depart from Duffie, Eckner, Horel and Saita (2008) by assuming different scenarios of data structure. Bayesian approach has been used to modify part of the parameter uncertainty. If the data history matters, then we would expect to see the portfolio-loss estimation result affected dramatically by different data structures.

\section{Frailty Correlated Default Model and Simulation Method}

One firm default status may have impact on another firm's default probability. Acharya, Schaefer, and Zhang (2008) clearly documents the impact of GM and Ford downgrade on the entire market constituents, even though some of them are completely unrelated to GM and Ford. Jorion and Zhang (2007) conduct a larger scale analysis over bankruptcies and find similar results. The reason for this seemingly unrelated firms sharing default factor can be learning, as argued by Collin-Dufresne, Goldstein, and Helwege (2003) and Giesecke (2004) or market structure as argued by Allen and Carletti (2006).

\subsection{Dynamic Frailty Model}

Motivated by the definitive finding of excessive default correlation by Das, Duffie, Kapadia, and Saita (2007), Duffie, Eckner, Horel and Saita (2008) proposed a frailty correlated default model. In such a reduced-form model, default intensity

$$
\begin{aligned}
\lambda_{i t} & =\Lambda\left(S_{i}\left(X_{t}\right) ; \theta\right) \\
& =e^{\alpha+\beta \cdot V_{t}+\vartheta \cdot U_{i t}+Y_{t}+Z_{i}}
\end{aligned}
$$


is driven by three types of factors: (1) observable market factors $\left(V_{t}\right)$ such as market stock returns and risk free rate. Demchuk and Gibson (2006) argue that stock market performance is an important credit spread determinant. (2) observable firm specific factors $\left(U_{i t}\right)$ such as distance-to-default and stock returns, Duffie, Saita, and Wang (2007) specifically examine the performance of distance-to-default. (3) unobservable "frailty" factors (market-wide $Y_{t}$ and firm specific $Z_{i}$ ). Details of this model is provided in Appendix A.

While long enough data history can help to tie down the model parameters, for relatively dynamic covariates, Bayesian approach must be used to incorporate progressively new information. That is to say, in this circumstance, the seemingly long data history is still limited to fix the parameters at certain points. Parameter uncertainty can be partially solved via Bayesian method. In default intensity estimation, Duffie, Eckner, Horel and Saita (2008) claims that the 25-year data set contains relatively few recorded defaults since public firms rarely go bankruptcy. Thus instead of Maximum Likelihood Estimation, we employ Bayesian Method in the model parameter estimation.

\subsection{Simulation Approach}

Historical data plays a critical role in the empirical investigation. With relatively limited data history, the model estimation may be sensitive to the data structures. To assess the data structure effect on the model estimation results, we simulate a series of data structures, each of which accompanies with a specific economic scenarios.

Specifically, different pattern of default may account for different data structures. During economic recession, there might be more insolvency bankruptcy and during some financial crisis (like the 2007-2008 credit crisis), there might be more liquidity defaults. Different types of defaults correspond to different data structure of distance to default and trailing stock return, which are the main observable firm-specific default-prediction covariates in the model. Then for insolvency default, the firm tends to have lower Trailing return and lower Distance to default. But for liquidity default, Trailing Return and Distance to default seem to be higher.

To generate the various scenarios, we assume that all observable factors follow the 
one stage autoregressive and Gaussian process, that is $\mathrm{AR}(1)$. The frailty factor is assumed to follow an Ornstein-Uhlenbeck (OU) process. This assumption is consistent with that of Duffie, Eckner, Horel and Saita (2008).

Before generating, however, it is worthy to remind the correlation among the data series. Although we have assumed that the time series of the observable factors is independent with the dynamic frailty process, there are correlation among some of the observable covariates. Then when simulating data, instead of generating AR(1) time series data independently, it is necessary to taking into account these potential correlations.

Specifically, for the observable factors we assume that they are modeled by the AR(1) process as follows. For the S\&P 500 return and the 3-month Treasury rates, we have

$$
\begin{aligned}
& \left(S P_{t}-u_{s p}\right)=\Phi_{s p}\left(S P_{t-1}-u_{s p}\right)+\delta_{s p} \varepsilon_{s p, t} \\
& \left(T R_{t}-u_{t r}\right)=\Phi_{t r}\left(T R_{t-1}-u_{t r}\right)+\delta_{t r} \varepsilon_{t r, t}
\end{aligned}
$$

where $\mathrm{u}$ stands for the long run mean of the time series process, and $\delta$ is the volatility of the normal distributed errors in each period. Both $\mathrm{u}$ and $\delta$ are constants in the formula, that is they are of the same value for each periods. $\Phi$ represents the first order autocorrelation coefficient. $\varepsilon$ follows the standard Brownian Motion. Following Duffie, Saita and Wang (2007) and Duffie, Eckner, Horel and Saita (2008), we assume that the Brownian Motion part of these two process are independent.

The firm's trailing 1-year stock return and Distance to default (DD) are modeled by

$$
\begin{aligned}
& \left(R_{i t}-u_{r_{i}}\right)=\Phi_{r_{i}}\left(R_{i, t-1}-u_{r_{i}}\right)+\delta_{r_{i}} \varepsilon_{r_{i}, t} \\
& \left(D D_{i t}-u_{d d_{i}}\right)=\Phi_{d d_{i}}\left(D D_{i, t-1}-u_{d d_{i}}\right)+\delta_{d d_{i}} \varepsilon_{d d_{i}, t} .
\end{aligned}
$$

where the $\mathrm{u}, \delta, \Phi$, and $\varepsilon$ represent the same meaning as that in formula (1) and (2) for the time series process.

To incorporate the data correlation, the Brownian Motion parts of firm's trailing 
1-year stock return and Distance to default are modeled as

$$
\begin{aligned}
& \varepsilon_{r_{i}, t}=\rho_{r, s p} \varepsilon_{s p, t}+\sqrt{1-\rho_{r, s p}^{2}} \nu_{t} \\
& \varepsilon_{d d_{i}, t}=\rho_{d d, r} \varepsilon_{r_{i}, t}+\sqrt{1-\rho_{d d, r}^{2}} \zeta_{t}
\end{aligned}
$$

where $\rho_{r, s p}$ are the correlation coefficient between the Brownian Motion process of $\varepsilon_{r_{i}, t}$ and $\varepsilon_{s p, t}$, and $\rho_{d d, r}$ represent the correlation coefficient between $\varepsilon_{d d, t}$ and $\varepsilon_{r_{i}, t}$. Based on the historical data, we set $\rho_{r, s p}=0.3$ and $\rho_{d d, r}=0.5$ in our simulating. $\nu_{t}, \zeta_{t}$ are independent Brownian Motion.The details for the estimation is provided in the appendix. This completes the correlation structure of our model.

\subsection{Data Generating Process}

In this part, we specify how the correlation coefficients, long run means, mean-reverting speeds, volatilities and initial values of the observable factors are loaded. We setup a relative simple whereas reasonable covariate time series structure in light of Duffie, Saita and Wang (2005). 3-month treasury rate is regarded as a monetary shock to the economy and is of some arbitrary nature. Although common wisdom would impose positive correlation between 3-month treasury rate and some macroeconomic condition factor, say, the S\&P 500 index, we assume these two covariates to be independent. The reason for this is that we actually use the 1-year SP 500 index trailing return which refers to a longer time horizon as to 3-month treasury rate and thus blurs the correlation structure. In addition, individual firm equity trailing return is correlated with the market index and distance to default is even more highly correlated with the firm equity return. Without much loss of sensibility, we define the correlation between 1-year S\&P 500 trailing return and individual firm 1-year trailing equity return to be 0.3 and the correlation between 1 -year trailing equity return and distance to default to be 0.5 .

In Duffie, Saita and Wang (2005), distance to default across firms shares the same positive mean-reverting speed which captures the leverage targeting, and the same volatility which is implied in the Merton theory. However, we have no reason to assume homogeneous long run mean among all firms. The way to load this long run mean for each firm is to draw from a uniform interval, which is the interquartile range esti- 
mated as $(1.4,4.8)$. The rough range of 1-year distance to default for investment grade bonds (BBB-AAA) is $(5.5,10.7)$ and for junk bonds $(\mathrm{CC}-\mathrm{BB})$ is $(0.6,3.3)$. For economic state comparison, we shift the lower bound of the quartile to 0.6 and the upper bound to 10.7, respectively for bad and good macroeconomic condition. The long run means of S\&P 500 trailing return, 3-month treasury rate and firm-specific equity return are assumed to be lower in bad economic state and higher in good economic state. For the normal situation, we set the values to be near their estimated counterparts from the historic real data.

For 1-year S\&P 500 index trailing return and equity 1-year trailing return, we can show that the one step autocorrelation is roughly 11/12 on condition that indice and stock prices follow GBM. Therefore, the mean-reverting speeds are unanimously taken to be $1-11 / 12=1 / 12$ across all sectors and for both of the trailing returns. The deriving of the one step autocorrelation is as follows. For the correlation between $R_{t}$ and $R_{t+1}$, since

$$
\begin{aligned}
& R_{t}=r_{t}+r_{t+1}+\cdots+r_{t+11} \\
& R_{t+1}=r_{t+1}+r_{t+2}+\cdots+r_{t+12}
\end{aligned}
$$

where $r_{t}$ follows a standard Geometric Brownian Motion, with

$$
E\left(r_{t}\right)=u, \quad \operatorname{Var}\left(r_{t}\right)=\sigma^{2}, \quad E\left(r_{t}^{2}\right)=u^{2}+\sigma^{2}
$$

then

$$
\begin{aligned}
& E\left(R_{t}\right)=12 u, \operatorname{Var}\left(R_{t}\right)=12 \sigma^{2} \\
& \operatorname{Cov}\left(R_{t}, R_{t+1}\right) \\
& =E\left(R_{t} \cdot R_{t+1}\right)-E\left(R_{t}\right) E\left(R_{t+1}\right) \\
& =11\left(u^{2}+\sigma^{2}\right)+133 u^{2}-144 u^{2} \\
& =11 \sigma^{2}
\end{aligned}
$$


With this result, the correlation between $R_{t}$ and $R_{t+1}$ can be written as

$$
\begin{aligned}
& \rho_{R_{t}, R_{t+1}} \\
& =\frac{\operatorname{Cov}\left(R_{t}, R_{t+1}\right)}{\sqrt{12 \sigma^{2}} \cdot \sqrt{12 \sigma^{2}}} \\
& =\frac{11 \sigma^{2}}{12 \sigma^{2}}=\frac{11}{12}
\end{aligned}
$$

From historic data, mean-reverting speed and volatility of 3-month treasury rate, and volatility of S\&P 500 index trailing return are estimated to be 0.0145, 0.47 and 0.0653, respectively. Volatilities of firms are drawn from a uniform interval $(20 \%, 50 \%)$. The mean-reverting speed and volatility of distance to default suggested in Duffie etc. is 0.0355 and 0.346 , respectively. The initial values of these four observable factors are fixed at their long run means. Table 1 summarizes the specification for long run means.

We simulate the times series for all the factors based on the above parameters governing the joint distribution of these covariates. To further get the default scenario, we generate a pre-set latent path with mean-reverting speed 0.03 and volatility 0.15 . We take these values out from the marginal posterior densities in Figure 6 in Duffie, Eckner, Horel and Saita(2008). Now the default intensities for firm i at time $t$ is calculated as

$$
\lambda_{i t}=e^{\alpha+\beta_{1} D D_{i t}+\beta_{2} R_{i t}+\beta_{3} T R_{t}+\beta_{4} S P_{t}+y_{t}}
$$

$\alpha, \beta$ could be chosen with some flexibility. Say $(\alpha, \beta)=(-1,-1.2,-0.65,-0.26,1.6)$, which is close to the real data output reported in Table II in Duffie, Eckner, Horel and Saita (2008).

Default arrival is identified when intensity times the forecast horizon reaches a random threshold. In detail, for each time $t$ and each firm $\mathrm{i}$, we draw a random number from $\mathrm{U}(0,1)$ and then let a firm go default when its intensity times the time window exceeds the random number. 


\subsection{Validation Tests}

As shown in Figure 5 of Duffie, Eckner, Horel and Saita (2008), the latent factor plays a crucial role in the tails of the probability densities of predicted number of defaults in the future 5 years. Common source of the current level and future shocks of this latent factor enlarges the risk of heavily clustered defaults remarkably. Thus the filtered-out latent factor path and the mean-reverting speed, kappa, and volatility, Eta, which govern the time series of the latent factor, are of the most gravity to assess the modeled correlation risk. However, we have little knowledge regarding where this latent factor stems from and what the time series behavior it should present. It is precarious to use this model before some tests with its actual power to capture the real situation.

The two potential sources of model vulnerability that occur to us firstly in mind are that the model might over-evaluate the latent path when it is actually not significant and/or under-evaluate when it does persist. Regarding these two concerns, we conduct two model fittings to testify the capturability. The observable covariates time series used here are the same for both tests. The simulated 1-year S\&P 500 index trailing return and 3-month treasury rate are shown in figure 1 . We differ when generating two default scenarios by not adding frailty into one of them. We define the scenario with frailty as I and the one without scenario as II. Then we apply the frailty model to both of the two scenarios. The sum of default intensities across firms and actual defaults at each time point for scenario I are shown in figure 2. The The estimation results are shown in Table 2, 3, 4 and 5 .

For scenario I with frailty, we can see that the filtered latent factor tightly follows the pre-set path. The parameters estimated are all highly significant. Whereas, as for scenario II, the estimated kappa and eta are not significant and the latent factor narrows down to around 0 . In both scenarios, the parameters estimated from traditional model

without frailty and the frailty model do not represent large jumps. It is relatively safe to conclude that the model appropriately pins down the intangible risk embedded in the unobservable latent factor which has a wide influence on the whole economy. 


\section{Simulation Results}

Duffie, Eckner, Horel, and Saita (2008) show that the frailty model estimated by the Gibbs sampler performs well with historical data. In this section, we demonstrate the effects of model specification and data history using the frailty model.

\subsection{Model Uncertainty Effects}

\subsubsection{Model Mis-specification}

Apart from the data history, we still have different estimation results when different models are fitted to make prediction. This new frailty model enhances our ability to tie down the latent sources of correlated risk. Whether it does a better work than the traditional double-stochastic intensity model remains unclear. In this part, we do a comparison between the traditional model and the frailty model. We estimate the traditional model with 5, 10 and 30 years' data history, respectively. The distribution of the predict default proportion are shown in figure 6 . We can see that the traditional model is not sensitive to the length of data history, in respect to the distribution tail. And it generate little right fat tail.

Even for single-obligor credit risk modeling, there is no consensus on the best performing model. Model failure has been recorded in nearly all areas. The seminal work on Vasicek (1987) on portfolio credit risk is also shown to be inaccurate for heterogenous asset pools (Hanson, Pesaran, and Schuermann (2008)). More seriously, default correlation is assumed to be only driven by observable factors. This counterfactual assumption is widely adopted until recently. However, we believe existing CDOs are almost all evaluated based on this low correlation assumption.

In order to understand how much effect this error due to model uncertainty caused the CDO mispricing, we formally conduct analysis with frailty correlated default process as the true data generating process. However, the CDO evaluator is unaware of this feature and only consider the observable default factors such as distance-to-default, stock returns, and risk free rates. We further augment with different data availability of 5, 10, and 30 years. The results are plotted in Figure 6.

We make two observations from Figure 6. First, data history makes little difference 
when the mis-specified no-frailty model is used. The 5-year and 10-year default predictions are nearly identical. Even the 30-year data case does not make a significant difference for the right tail with large defaults. Second, the frailty and no-frailty results are qualitatively different. The tail of the frailty model predicted default distribution is much fatter than the tails of the no-frailty predictions. Default at $7 \%$ level is almost impossible for no-frailty case but with $5 \%$ probability for frailty model.

Above finding indicates that model uncertainty is much more important than data availability. While both issues played some roles in the CDO mispricing episode, the lack of accurate model was much more to be blamed. However, since CDO transactions are zero such games. Relative sophistication could potentially produce large profits. This rationale could explain the proliferation of retailed structured products. Essentially, investors with better credit models gain at others' losses.

Furthermore, while data history shortage can be mechanically resolved by extending the market sufficiently long, model uncertainty is arguably much more difficult to improve. Hence, for future financial innovation with complex products, disclosure becomes important as the learning process for new financial instruments can be slow. The consequence of little understood financial derivatives can indeed be massively destructive.

\subsubsection{Structural Breaks}

Andreou and Ghysels (2008) emphasize the effect of structural shifts to the credit risk structural model. Instead of fixing the structural model parameter at some points, they point out that it is necessary taking into account of the structural parameter variation. Failed to considering the effects, may results in biased inferences based on the credit model. An optimal sequential quality control procedural with minimum detecting time for monitoring the structural breaks is suggested, which is extremely useful for monitoring the corporation stability in financial distress period. Moreover, with a good

finite sample behavior as indicated in their simulation, the suggested procedure could be used for the quality control of the credit models. 


\subsection{Data History Effects}

\subsubsection{Length of Data history}

High quality data is the first concern when we are doing maximum likelihood estimation. Data structure might shift from decade to decade, even year by year. Limited historic data in deficiency of some extreme economic states leads to biased estimation results and sometimes is detrimental for prediction. The current credit crunch is frequently imputed to the financial innovations, like CDO and CDS, which are organized from models based on very short time-horizon data history. We lay out a data history test, exploiting the dynamic frailty model, to see how the length of data history will affect the tails of the predicted number of defaults probability density.

We truncate our dataset generated with frailty in the former validation test part to the last 10 and 5 years. 5-10 years is close to the actual data history of large volume issuance of CDO or CDS. Then we apply the frailty model to the limited data history. The parameter estimation results are presented in Table 6, 7 and 8, and the filtered latent factor is shown in figure 4 . We can see that as the data history becomes shorter, more parameters become insignificant. And the capturability of the model become weaker as the filtered latent factor deviates the pre-set path further. The most interesting part lies in the prediction for future default proportion. The tail of the distribution shrinks as the data history becomes shorter. For 30 years' data, the $95 \%, 99 \%$ and 99.5\% percentile is $7.30 \%, 9.43 \%$ and $10.04 \%$, respectiely. However, for limited 5 years' data, these percentiles abate to $5.46 \%, 6.3 \%$ and $6.59 \%$, respectively. The CDO $10 \%$ $30 \%$ Mezzanine tranche still gets a chance to be reached based on the 30 years' history, though not for 10 and 5 years.

\subsubsection{Data Realization of Economic States}

Macro economic condition has long been regarded as very important for individual firm performance. During financial or economic crisis, contagion effect will largely absorb the liquidity in the market and defaults happen thereafter. Another dimension of bias of our model estimation comes from the economic state within the history of the dataset. If we are luckily living in a thriving 30-years, the data for these 30 years will tell us 
nothing about the severe problems encountered in an economic recession. Accordingly, we apply a economic state analysis with the frailty model. The way to do it is to shift down the long run means of firm-specific distance to default, firm-specific trailing equity return, S\&P 500 index trailing return, and the 3-month treasury rate to represent a bad economic state and elevate the long run means to represent a good economic state. The actual predicted number of defaults in bad, normal and good economic states are 1048, 586 and 196, respectively. The estimation results are reported in Table 9, 10, 11. The distribution of the predicted number of defaults are shown in figure 5 .

As we expect, the both the mean and right tail of the loss distribution increases as the economic state deteriates. For good economic condition, the 50\%, 95\%, 99\% and $99.5 \%$ percentile is $1.3 \%, 3.0 \%, 4.1 \%$ and $4.5 \%$, respectiely. However, for bad economic condition, these percentiles bound up to $10.6 \%, 22.5 \%, 29.3$ and $32 \%$, respectively. The CDO 15\%-30\% senior tranche might be wiped out if extreme bad recession happens.

\subsubsection{Data Estimation Error}

The estimation of distance to default might deviate from the true value since we could only get periodic and noisy accounting data. Duffie and Lando (2001) provide that noise in distance to default reshapes the term structure of credit spreads of corporate bonds. Firms might jump to default even in a very short maturity. Distance to default estimation error is also a source of the frailty factor. Imperfect information lead to addtional risk in the firm. Systematic biases in distance to default estimation can be capture by the frailty path. Here we do not include systematic error in distance to default estimation, simply because we already add the frailty path to our model. We want to test whether the filter can work properly if the estimation contains some white noise. The ususal way to perform noise test is to engage the signal to noise ratio, which is the proportion of the standard deviation of the signal to that of the noise. We add a $10 \%$ and $20 \%$ white noise to the true diatance to default, corresponding to signal to noise ratio 10 and 5, respectively. And we make adjustment to the distance to default value to ensure the total standard deviation after adding the noise does not change. The parameter estimation and predicted default proportion are shown in Table 12 and figure 7 respectively.

We can see that the parameter estimation remains nearly the same as the true model. 
And the predicted default proportion does not change much in shape and position, either. Therefore, we conclude that unsystematic noise in distance to default estimation is not an important issue in the frailty model. The frailty model display high robustness to white noise in distance to default estimation.

\section{Empirical Evidence: A CDO Case Study}

In this part we will apply the dynamic frailty model for real CDO tranches default estimation. FREEDOM CCS 2008-1 is selected as a check, with closing date on March 30, 2008 and stated maturity on November 15, 2016. The issuer of this CLO is Lehman Brother Inc. and the participation counterparty guarantor is Lehman Brother Holdings Inc. This CDO was amended before May 7, 2008. Its closing date amount is about 2.8 billion, but the amount after amendment is about 1.9 billion. The proportion of the A tranche remains the same, $80 \%$ of the total principal. One mezzanine tranche with $\mathrm{B}+$ rating was added after amendment. Both have arating higher than the weighted average rating B-. The number of assets after amendment is 28 .

We apply the dynamic frailty model and the traditional model without frailty to this CLO. There is a rough relation between rating and distance to default. We assume the underlying assets are of the same face value and with the weighted average rating. Long run mean of Distance to default is chosen to be the one reported in the paper. We calculate the number of assets before amendment with proportion to CLO amount before and after amendment. We generate the predicted default probability and percentiles in Figure 8 and Table 13.

We can see that under the no frailty model, the asset pool before amendment can just produce $64 \% \mathrm{~A}$ tranche. However, it gives $73 \% \mathrm{~A}$ tranche after amendment. The frailty model would allow only 51\% A tranche even after amendment.

\section{Conclusion}

Understanding the ongoing credit crisis is important for future regulatory and monitoring policies as well as risk management strategies. The CDO market was not well equipped 
with sufficient data for back-testing and accurate model. Our study shows that these two factors, especially the latter, contributed significantly to the poor portfolio credit risk valuation and CDO mispricing.

Specifically, we employ a frailty correlated default model of Duffie, Eckner, Horel, and Saita (2008) for MCMC simulation exercises. Knowing the true data generating dynamics, we can better pin down the casuality of CDO pricing failures. Not only was data history a problem, the random realization of economic states will also present false picture of predicted default scenarios. Moreover, lack of accurate model exacerbates the data limitation and could result in qualitatively different assessment. The often accoladed AAA rating could actually of single-A quality.

The Bayesian approach used in this study is useful for portfolio credit risk analysis as data is often scarce. Expert opinion or prior belief then becomes critical. For example, given our understanding of paucity AAA ratings, it should be obvious that the abundance of AAA ratings in CDO market is incredible. We plan to take this approach to actual $\mathrm{CDO}$ deals and incorporate the learning feature in CDO valuation. 


\section{Appendices}

\section{A Dynamic Frailty Model}

Following Duffie, Eckner, Horel, and Saita(2008), our estimation employs the dynamic frailty model. The model's objective is to estimate the probability distribution of the number of defaults among $m$ given firms over any prediction horizon. For a specific firm, we include a set of observable factors $W_{i t}$, and a common unobservable latent factor $Y_{t}$ whose effect is referred as frailty in statistical literature.

Specifically, we include the firm specific distance to default(DD) and the firm's one year trailing stock return as the observable firm specific default-prediction covariates, and use vector $U_{i t}$ denote these factors. For the observable macro-economic defaultprediction covariates, vector $V_{t}$, we use the 3 -month Treasury bill rate and the trailing one year return on the S\&P 500 index in the model. Additional observable macroeconomic variables can be included for robustness checks. Last but not least, a common dynamic frailty covariate, $Y_{t}$, is included to capture the unobservable default correlation among the firms in the underlying portfolio.

Similar to Duffie, Eckner, Horel, and Saita(2008), we define a Markov state Vector $X_{t}$ which include both the firm-specific and macroeconomic covariates $U_{i t}, V_{t}$ and $Y_{t}$. If $X_{t}$ is absolutely observable, the default intensity $\lambda_{i t}$ for a given firm i at time $\mathrm{t}$ will be

$$
\begin{aligned}
\lambda_{i t} & =\Lambda\left(S_{i}\left(X_{t}\right) ; \theta\right) \\
& =e^{\alpha+\beta \cdot V_{t}+\vartheta \cdot U_{i t}+Y_{t}+Z_{i}}
\end{aligned}
$$

where $S_{i}\left(X_{t}\right)$ represents the component of $X_{t}$ that is relevant to the default intensity of firm i, $\theta$ represents the parameter vector for default intensity to be estimated. Note that $Z_{i}$ in the equation represents firm specific latent factor, and is intended to allowing for unobserved heterogeneity. As shown in Duffie, Eckner, Horel, and Saita(2008), in the extended dynamic frailty model with $Z_{i}$, the estimation results do change much. 
Therefore, we do not include it in the model estimation.

To involve the frailty effect, however, we assume that $X_{t}$ is only partially observable. For simplicity, let $W_{i t}=\left(1, U_{i t}, V_{t}\right)$, that is the vector of all observable covariates for firm i's default intensity function. Then $S_{i}\left(X_{t}\right)=\left(\mathrm{W}_{i t}, Y_{t}\right)$, where $Y_{t}$ represent the common unobservable frailty factor. Then the default intensity takes the matrix form of

$$
\begin{aligned}
\lambda & =\Lambda(S(X) ; \theta) \\
& =\Lambda((w, y) ; \theta)=e^{\beta_{1} w_{1}+\cdots+\beta_{n} w_{n}+\eta y}
\end{aligned}
$$

where $w$ represents the vector of observable factors for all companies.

To complete the model construction, following Duffie, Saita and Wang (2007) and Duffie, Eckner, Horel, and Saita (2008), we specify a set of time-series model for the covariates in the state vector $X_{t}$. For covariates in $W_{i t}$, we opt for a one stage autoregressive and Gaussian process. The parameter vector of these time series is denoted as $\gamma$, which can be estimated through traditional maximum likelihood method as detailed in Duffie, Saita and Wang (2007). For the frailty factor $Y_{t}$, we suppose it follows a simple Ornstein-Uhlenbeck (OU) process with a non-negative constant mean reversion rate $\kappa$ and standard Brownian motion B. That is

$$
d Y_{t}=-\kappa Y_{t} d t+d B_{t}, \quad Y_{0}=0
$$

The reason why $Y_{t}$ is assumed to follow the OU process, as suggested by Duffie, Eckner, Horel, and Saita (2008), lies in the fact that it can capture the decaying but accumulative effect of various types of unobservable common shocks to the default intensities over time. However, it is worth to note that given the unobservable historical sample path of $Y_{t}$, even with the relatively long data set, such as 25 years in Duffie, Eckner, Horel, and Saita (2008), it is still too limited to be used to tie down its time series parameter. Besides, as shown in the formula, the original value as well as the long-run mean of $Y_{t}$ is assumed to be zero. The underlying logic is again similar to that of Duffie, Eckner, Horel, and Saita (2008). 
The question left is the estimation of model parameters $(\gamma, \theta)$. As specified above, $\gamma$ is the parameter vector determining the time-series behavior of the observable covariates. $\theta$ represents the parameter vector for default intensity, where $\theta=(\beta, \eta, \kappa)$. The likelihood of the data at the parameters $(\gamma, \theta)$ is given by

$$
\begin{aligned}
& \mathcal{L}(\gamma, \theta \mid W, Y, D) \\
& =\mathcal{L}(\gamma \mid W) \mathcal{L}(\theta \mid W, Y, D) \\
& =\mathcal{L}(\gamma \mid W) \prod_{i=1}^{m}\left(e^{-\sum_{t=t_{i}}^{T_{i}} \lambda_{i t} \Delta t} \prod_{t=t_{i}}^{T_{i}}\left[D_{i t} \lambda_{i t} \Delta t+\left(1-D_{i t}\right)\right]\right)
\end{aligned}
$$

By implementing the independent hypothesis for $\mathrm{W}$ and $\mathrm{Y}$ process, the likelihood can be rewrote as

$$
\begin{aligned}
& \mathcal{L}(\gamma, \theta \mid W, D) \\
& =\int \mathcal{L}(\gamma, \theta \mid W, y, D) p_{Y}(y) d y \\
& =\mathcal{L}(\gamma \mid W) \int \mathcal{L}(\theta \mid W, y, D) p_{Y}(y) d y \\
& =\mathcal{L}(\gamma \mid W) E\left[\prod_{i=1}^{m}\left(e^{-\sum_{t=t_{i}}^{T_{i}} \lambda_{i t} \Delta t} \prod_{t=t_{i}}^{T_{i}}\left[D_{i t} \lambda_{i t} \Delta t+\left(1-D_{i t}\right)\right]\right) \mid W, D\right] .
\end{aligned}
$$

where $\mathrm{D}$ is the vector of default indicators. That is, for company i, $D_{i}=0$ before default, and 1 if default occurs and thereafter. $p_{Y}(y)$ represents the unconditional probability density of the unobservable common factor $\mathrm{Y}$.

Considering the unobservable sample process for $\mathrm{Y}$, the model parameters are estimated through a combination of EM algorithm and the Gibbs sampler, similar to that employed by Duffie, Eckner, Horel, and Saita (2008). Appendix B provides some detailed explanation. 


\section{B Parameter Estimation}

The dynamic frailty model parameters $(\gamma, \theta)$ are estimated in the similar way as Duffie, Saita and Wang (2007) and Duffie, Eckner, Horel and Saita (2008). Specifically, vector $\gamma$, which determines the dynamic process of observable covariates as described above, is estimated by maximum likelihood estimation.

For estimating the default intensity parameter $\theta=(\beta, \eta, \kappa)$, a combination of Markov chain Monte Carlo (MCMC) and the expectation-maximization (EM) algorithm is employed. This combination has advantage for the Maximum likelihood parameter estimation in the model with incomplete information. The detailed steps include

Step 1. Get the maximum likelihood estimator of the intensity model with only observable covariates $\hat{\beta}$. That is the MLE from equation (10) without considering the effect of unobservable covariate $\mathrm{Y}$.

Step 2. Assign an initial estimate value for $\theta$, as suggested by Duffie, Eckner, Horel and Saita $(2008)$, at $\theta^{(0)}=(\hat{\beta}, 0.05,0)$.

Step 3. Draw $\mathrm{n}$ independent sample path for the frailty factor $Y^{(1)}, \ldots, Y^{(n)}$ from $p_{Y}\left(\cdot \mid W, D, \theta^{l}\right)$, that is the conditional density of Y's OU process. This can be down with MCMC, specifically Gibbs sampler, while taking the $l^{\text {th }}$ estimate value for $\theta^{l}$ as well as the observable covariates $\mathrm{W}$ and $\mathrm{D}$ as given.

Step 4. Maximization step. Define the intermediate quality

$$
\begin{aligned}
Q\left(\theta, \theta^{(l)}\right) & =E_{\theta^{(l)}}(\log \mathcal{L}(\theta \mid W, Y, D)) \\
& =\int \log \mathcal{L}(\theta \mid W, y, D) p_{Y}\left(y \mid W, D, \theta^{(l)}\right) d y
\end{aligned}
$$


Based on the sample path for Y drawn in step $3, Q\left(\theta, \theta^{(l)}\right)$ can be approximated by

$$
\hat{Q}\left(\theta, \theta^{(l)}\right)=\frac{1}{n} \sum_{j=1}^{n} \log \mathcal{L}\left(\theta \mid W, Y^{(j)}, D\right)
$$

Then the new parameter estimate $\theta^{(l+1)}$ can be get by

$$
\operatorname{Max} \hat{Q}\left(\theta, \theta^{(l)}\right)=\operatorname{Max} \frac{1}{n} \sum_{j=1}^{n} \log \mathcal{L}\left(\theta \mid W, Y^{(j)}, D\right)
$$

Step 5. Back to step 3, and replace $\theta^{(l)}$ with the new estimator $\theta^{(l+1)}$. Proceed to step 4 to get $\theta^{(l+2)}$. Repeating step 3,4 , until the estimation of $\theta$ reasonable convergence.

The asymptotic standard errors for the parameter estimators can be calculate from the Hessian matrix of the expected complete-data likelihood in equation (13).

\section{Correlation Structure of Observable Factors}

This appendix explains details of how we simulating the time series data for observable factors including S\&P 500 stock return, 3-month Treasury bill rate, firm's distance to default and 1-year trailing stock return. It is worth to note the formal definition of Distance to default, that is for firm $i$ at time $t$ we have

$$
D D_{i t}=\frac{\ln \left(\frac{V_{i t}}{L_{i t}}\right)+\left(\mu_{i A}-\frac{1}{2} \sigma_{i A}^{2}\right) T}{\sigma_{i A} \sqrt{T}}
$$

where $\mathrm{T}$ is the forecast horizon, $V_{i t}$ and $L_{i t}$ are the firm i's asset value and liability at time t, respectively. $\mu_{i A}$ and sigma $_{i A}$ represent the firm's asset growth rate and volatility.

For the correlated time series generating, it can be shown that for any Brownian

motion $\epsilon_{1}, \epsilon_{2}$, define $\epsilon_{3}=\rho \epsilon_{1}+\sqrt{1-\rho^{2}} \epsilon_{2}$. Then we have $\epsilon_{3}$ also follows a Brownian 
motion, with

$$
\begin{aligned}
& \rho\left(\epsilon_{1}, \epsilon_{3}\right) \\
& =E\left[\left(\epsilon_{1}-E\left(\epsilon_{1}\right)\right) \cdot\left(\epsilon_{3}-E\left(\epsilon_{3}\right)\right)\right] \\
& =E\left(\epsilon_{1} \cdot \epsilon_{3}\right) \\
& =\rho E\left(\epsilon_{1}^{2}\right)+\left(1-\rho^{2}\right) E\left(\epsilon_{1} \epsilon_{2}\right) \\
& =\rho
\end{aligned}
$$

For two stationary time series process $a_{t}, b_{t}$ we have

$$
\begin{aligned}
& \left(a_{t}-u_{a}\right)=\Phi_{a}\left(a_{t-1}-u_{a}\right)+\delta_{a} \varepsilon_{a, t} \\
& \left(b_{t}-u_{b}\right)=\Phi_{b}\left(b_{t-1}-u_{b}\right)+\delta_{b} \varepsilon_{b, t}
\end{aligned}
$$

where $\mathrm{u}$ stands for the long run mean of the time series process, and $\delta$ is the volatility of the normal distributed errors in each period. Both $\mathrm{u}$ and $\delta$ are constants in the formula, that is they are of the same value for each periods. $\Phi$ represents the first order autocorrelation coefficient, and lies between 0 and 1. $\varepsilon$ follows the standard Brownian Motion. However, we assume that $\varepsilon_{a, t}$ and $\varepsilon_{b, t}$ are correlated with $\rho\left(\varepsilon_{a, t}, \varepsilon_{b, t}\right)=\rho$.

For the correlation between $a_{t}$ and $b_{t}$, it can be shown that

$$
\rho\left(a_{t}, b_{t}\right)=\frac{\operatorname{cov}\left(a_{t}, b_{t}\right)}{\delta_{a t} \cdot \delta_{b t}}=\frac{\operatorname{cov}\left(a_{t}-u_{a}, b_{t}-u_{b}\right)}{\delta_{a t} \cdot \delta_{b t}}
$$

where $\delta_{a t}=\frac{\delta_{a}}{\sqrt{1-\Phi_{a}^{2}}}, \delta_{b t}=\frac{\delta_{b}}{\sqrt{1-\Phi_{b}^{2}}}$

$$
\begin{aligned}
& \operatorname{cov}\left(a_{t}-u_{a}, b_{t}-u_{b}\right) \\
& =E\left(\left(a_{t}-u_{a}\right) \cdot\left(b_{t}-u_{b}\right)\right)-E\left(a_{t}-u_{a}\right) \cdot E\left(b_{t}-u_{b}\right) \\
& =\Phi_{a} \Phi_{b} E\left(\left(a_{t-1}-u_{a}\right) \cdot\left(b_{t-1}-u_{b}\right)\right)+\delta_{a} \delta_{b} E\left(\varepsilon_{a, t} \varepsilon_{b, t}\right) \\
& =\Phi_{a} \Phi_{b} E\left(\left(a_{t-1}-u_{a}\right) \cdot\left(b_{t-1}-u_{b}\right)\right)+\delta_{a} \delta_{b} \rho
\end{aligned}
$$


Since $a_{t}, b_{t}$ are stationary, so $\operatorname{are}\left(a_{t}-u_{a}\right),\left(b_{t}-u_{b}\right)$ and $\left[\left(a_{t}-u_{a}\right) \cdot\left(b_{t}-u_{b}\right)\right]$,then

$$
\begin{aligned}
& E\left[\left(a_{t-1}-u_{a}\right) \cdot\left(b_{t-1}-u_{b}\right)\right] \\
& =E\left[\left(a_{t}-u_{a}\right) \cdot\left(b_{t}-u_{b}\right)\right] \\
& =\operatorname{cov}\left(a_{t}-u_{a}, b_{t}-u_{b}\right)
\end{aligned}
$$

Use this result in equation (14)

$$
\operatorname{cov}\left(a_{t}-u_{a}, b_{t}-u_{b}\right)=\frac{\rho \delta_{a} \delta_{b}}{1-\phi_{a} \phi_{b}}
$$

Incorporate this result together with $\delta_{a t}, \delta_{b t}$ in equation (13), we have

$$
\rho\left(a_{t}, b_{t}\right)=\frac{\sqrt{\left(1-\phi_{a}^{2}\right)\left(1-\phi_{b}^{2}\right)}}{1-\phi_{a} \phi_{b}} \cdot \rho
$$

Given $\phi_{a}$ and $\phi_{b}$, that is the speed of mean reverting, we can change $\rho$ to control the correlation between $a_{t}$ and $b_{t}$. For $\phi$ approaches to one, the correlation between $a_{t}$ and $b_{t}$ can be approximated by $\rho$. 


\section{References}

Acharya, Viral V., Stephen Schaefer, and Yili Zhang, 2008, Liquidity risk and correlation risk: A clinical study of the General Motors and Ford downgrade of May 2005, Working paper, LBS.

Allen, Franklin, 2008, Lessons from the crisis, Presidential Address, International Atlantic Economic Society.

Allen, Franklin, and Elena Carletti, 2006, Credit risk transfer and contagion, Journal of Monetary Economics 53, 89-111.

Andreou, Elena, and Eric Ghysels, 2008, Quality control for structural credit risk models, Journal of Econometrics 146, 364-375.

Bank for International Settlements (BIS), 2008, Ratings in structured finance: What went wrong and what can be done to address shortcomings?

Berd, Arthur, Robert Engle, and Artem Voronov, 2007, The underlying dynamics of credit correlation, Journal of Credit Risk 3(2), 27-62.

Bonfim, Diana, 2008, Credit risk drivers: Evaluating the contribution of firm level information and of macroeconomic dynamics, Journal of Banking $\&$ Finance, forthcoming.

Brennan, Michael J., Julia Hein, and Ser-Huang Poon, 2008, Tranching and rating, Working paper, UCLA.

Brunnermeier, Markus, 2008, Deciphering the 2007-08 liquidity and credit crunch, Journal of Economic Perspectives, forthcoming.

Chen, Ren-Raw, and Ben J. Sopranzetti, 2003, The valuation of default-triggered credit derivatives, Journal of Financial and Quantitative Analysis 38, 359382 .

Coval, Joshua D., Jakub W. Jurek, and Erik Stafford, 2008, Economic Catastrophe Bonds, American Economic Review, forthcoming.

Coval, Joshua D., Jakub W. Jurek, and Erik Stafford, 2009, The economics of structured finance, Working paper 09-060, Harvard Business School.

Collin-Dufresne, Pierre, Robert S. Goldstein, and Jean Helwege, 2003, Is credit event risk priced? Modeling contagion via the updating beliefs, Working paper. 
Cont Rama, 2006, Model uncertainty and its impact on the pricing of derivative instruments, Mathematical Finance 16, 519-547.

Crouhy, Michel G., Robert A. Jarrow, and Stuart M. Turnbull, 2008, The subprime credit crisis of 07, Journal of Derivatives 16(1), 81-110.

Das, Sanjiv R., Darrell Duffie, Nikunj Kapadia, and Leandro Saita, 2007, Common Failings: How Corporate Defaults are Correlated, Journal of Finance 62, 93-117.

DeMarzo, Peter M., 2005, The pooling and tranching of securities: A model of informed intermediation, Review of Financial Studies 18, 1-35.

Demchuk, Andriy, and Rajna Gibson, 2006, Stock market performance and the term structure of credit spreads, Journal of Financial and Quantitative Analysis $41,863-887$.

Duffie, Darrell, 2007, Innovations in credit risk transfer: Implications for financial stability, Working paper, Stanford University.

Duffie, Darrell, Andreas Eckner, Guillaume Horel, and Leandro Saita, 2008, Frailty Correlated Default, Journal of Finance, forthcoming.

Duffie, Darrell, and David Lando, 2001, Term Structures of Credit Spreads with Incomplete Accounting Information, Econometrica 69, 633-664.

Duffie, Darrell, Leandro Saita, and Ke Wang, 2007, Multi-period Corporate Default Prediction with Stochastic Covariates, Journal of Financial Economics 83, 635-665.

Eckner, Andreas, 2008, Risk Premia in Structured Credit Derivatives, Working Paper, Stanford University.

Feldhtter, Peter, 2008, An Empirical Investigation of an Intensity-Based Model for Pricing CDO Tranches, Working Paper, Copenhagen Business School.

Fender, Ingo, Nikola Tarashev, and Haibin Zhu, 2008, Credit fundamentals, ratings, and value-at-risk: CDOs versus corporate exposures, BIS Quarterly Review, March-2008.

Garlappi, Lorenzo, Raman Uppal, and Tan Wang, 2007, Portfolio selection with parameter and model uncertainty: A multi-prior approach, Review of Financial Studies 20, 41-81. 
Gibson, Rajna, 2000, Model Risk: Concepts, calibration, and valuation and pricing, Risk Books.

Giesecke, Kay, 2004, Correlated default with incomplete information, Journal of Banking \& Finance 28, 1521-1545.

Glasserman, Paul, Wanmo Kang, and Perwez Shahabuddin, 2007, Large deviations in multifactor portfolio credit risk, Mathematical Finance 17, 345-379.

Glasserman, Paul, and Jingyi Li, 2005, Importance sampling for portfolio credit risk, Management Science 51, 1643-1656.

Griffin, John, and Dragon Yongjun Tang, 2008, What Drove the Mismatch between Initial CDO Credit Ratings and Subsequent Performance? Bad Luck, Model Error, Misleading Inputs, or Agency Conflicts, Working paper, University of Texas at Austin and University of Hong Kong.

Hanson, Samuel G., M. Hashem Pesaran, and Til Schuermann, 2008, Firm heterogeneity and credit risk diversification, Journal of Empirical Finance 15, $583-612$.

Heitfield, Erik, 2008, Parameter Uncertainty and the Credit Risk of Collateralized Debt Obligations, Working Paper, Division of Research and Statistics Federal Reserve Board.

Hull, John C., 2008, The credit crunch of 2007: What went wrong? Why? What lessons can be learned? Working paper, University of Toronto.

Jimenez, Gabriel, and Javier Mencia, 2008, Modelling the distribution of credit losses with observable and latent factors, Journal of Empirical Finance, forthcoming.

Jorion, Phillip, and Gaiyan Zhang, 2007, Good and bad credit contagion: Evidence from credit default swaps, Journal of Financial Economics 84, 860-883.

Kiefer, Nicolas M., 2008, Default estimation for low-default portfolios, Journal of Empirical Finance, forthcoming.

Koopman, Siem Jan, Roman Kraussl, Andre Lucas, and Andre B. Monteiro, 2008, Credit cycles and macro fundamentals, Journal of Empirical Finance, forthcoming. 
Leland, Hayne E., 2007, Financial synergies and the optimal scope of the firm: Implications for mergers, spinoffs, and structured finance, Journal of Finance $62,765-807$.

Loffler, Gunter, 2003, The effects of estimation error on measures of portfolio credit risk, Journal of Banking \& Finance 27, 1427-1453.

Longstaff, Francis A., and Arvind Rajan, 2008, An Empirical Analysis of the Pricing of Collateralized Debt Obligations, Journal of Finance 63, 529-563.

McNeil, Alexander J., and Jonathan P. Wendin, 2007, Bayesian inference for generalized linear mixed models of portfolio credit risk, Journal of Empirical Finance 14, 131-149.

Mehran, Hamid, and Ren M. Stulz, 2007, The economics of conflicts of interests in financial institutions, Journal of Financial Economics 85, 267-296.

Merton, Robert C., 1974, On the Pricing of Corporate Debt: The Risk Structure of Interest Rates, Journal of Finance 29, 449-470.

Nicole, Antonio, and Loriana Pelizzon, 2008, Credit derivatives, capital requirements and opaque OTC markets, Journal of Financial Intermediation 17, 444-463.

Plosser, Charles I., 2008, Financial econometrics, financial innovation, and financial stability, Journal of Financial Econometrics, forthcoming.

U.S. Securities Exchange Commission (SEC), 2008, Summary report of issued identified in the Commission staff's examinations of select credit rating agencies.

Standard and Poor's, 2007, Structured finance commentary: The fundamentals of structured finance ratings.

Stulz, Rene M., 2008, Risk management failures: What are they and when do they happen, Working paper, Ohio State University.

Wang, Shaun, and Robert Brown, 1998, A frailty model for projection of mortality improvement, Journal of Actuarial Practice 6, 197-241.

Vasicek, Oldrich, 1987, Probability of loss on loan portfolio, Moody's KMV Corporation. 


\begin{tabular}{|l|c|c|c|c|}
\hline & S\&P & TR & DD & $R_{i}$ \\
\hline Good Economy & $18 \%$ & 6 & $\mathrm{U}(1.4,10.7)$ & $\mathrm{U}(13 \%, 21 \%)$ \\
\hline Normal Economy & $9 \%$ & 4 & $\mathrm{U}(1.4,4.8)$ & $\mathrm{U}(5 \%, 13 \%)$ \\
\hline Bad Economy & $0 \%$ & 2 & $\mathrm{U}(0.6,4.8)$ & $\mathrm{U}(-4 \%, 4 \%)$ \\
\hline
\end{tabular}

Table 1: Long run mean for the observable factors, (a) 1-year S\&P trailing return (S\&P), (b) 3 month treasury rate (TR), (c) firm's distance to default (DD), and (d) 1-year individual firm trailing stock return $\left(R_{i}\right)$.

\begin{tabular}{|l|r|r|r|}
\hline & Coefficient & Std. Error & t-statistic \\
\hline constant & -1.599 & 0.121 & -13.19 \\
\hline distance to default & -1.146 & 0.034 & -33.99 \\
\hline trailing stock return & -0.942 & 0.144 & -6.55 \\
\hline 3-month T-bill rate & -0.221 & 0.029 & -7.65 \\
\hline trailing S\&P 500 return & 0.833 & 0.270 & 3.08 \\
\hline latent-factor volatility $\eta$ & 0.138 & 0.018 & 7.47 \\
\hline latent-factor mean reversion $\kappa$ & 0.025 & 0.008 & 3.20 \\
\hline
\end{tabular}

Table 2: Maximum likelihood estimates of intensity-model parameters with frailty

\begin{tabular}{|l|r|r|r|}
\hline & Coefficient & Std. Error & t-statistic \\
\hline constant & -1.494 & 0.090 & -16.65 \\
\hline distance to default & -1.150 & 0.031 & -36.79 \\
\hline trailing stock return & -0.930 & 0.137 & -6.76 \\
\hline 3-month T-bill rate & -0.218 & 0.023 & -9.47 \\
\hline trailing S\&P 500 return & 0.907 & 0.258 & 3.51 \\
\hline
\end{tabular}

Table 3: Maximum likelihood estimates of intensity-model parameters without frailty 


\begin{tabular}{|l|r|r|r|}
\hline & Coefficient & Std. Error & t-statistic \\
\hline constant & -1.006 & 0.099 & -10.15 \\
\hline distance to default & -1.222 & 0.031 & -38.90 \\
\hline trailing stock return & -0.543 & 0.131 & -4.16 \\
\hline 3-month T-bill rate & -0.282 & 0.023 & -12.41 \\
\hline trailing S\&P 500 return & 1.949 & 0.248 & 7.88 \\
\hline latent-factor volatility $\eta$ & 0.023 & 0.014 & 1.60 \\
\hline latent-factor mean reversion $\kappa$ & 0.000 & 0.009 & 0.00 \\
\hline
\end{tabular}

Table 4: Maximum likelihood estimates of intensity-model parameters with frailty (data without frailty)

\begin{tabular}{|l|r|r|r|}
\hline & Coefficient & Std. Error & t-statistic \\
\hline constant & -0.990 & 0.083 & -11.85 \\
\hline distance to default & -1.223 & 0.029 & -42.73 \\
\hline trailing stock return & -0.544 & 0.115 & -4.74 \\
\hline 3-month T-bill rate & -0.282 & 0.020 & -13.90 \\
\hline trailing S\&P 500 return & 1.982 & 0.234 & 8.48 \\
\hline
\end{tabular}

Table 5: Maximum likelihood estimates of intensity-model parameters without frailty (data without frailty) 


\begin{tabular}{|l|c|c|c|}
\hline & 30 year & 10 year & 5 year \\
\hline \multirow{2}{*}{ constant } & -1.599 & -1.220 & -1.592 \\
& $(-13.19)$ & $(-3.49)$ & $(-3.18)$ \\
\hline \multirow{2}{*}{ distance to default } & -1.146 & -1.134 & -1.145 \\
& $(-33.99)$ & $(-16.97)$ & $(-12.24)$ \\
\hline \multirow{2}{*}{ trailing stock return } & -0.942 & -0.990 & -0.821 \\
& $(-6.55)$ & $(-3.32)$ & $(-1.88)$ \\
\hline \multirow{2}{*}{ 3-month T-bill rate } & -0.221 & -0.299 & -0.217 \\
& $(-7.65)$ & $(-3.90)$ & $(-2.07)$ \\
\hline \multirow{2}{*}{ trailing S\&P 500 return } & 0.833 & -0.012 & 0.165 \\
& $(3.08)$ & $(-0.02)$ & $(0.17)$ \\
\hline \multirow{2}{*}{ latent-factor volatility $\eta$} & 0.138 & 0.160 & 0.039 \\
& $(7.47)$ & $(2.94)$ & $(0.39)$ \\
\hline latent-factor mean re- & 0.025 & 0.146 & 0.370 \\
version $\kappa$ & $(3.20)$ & $(2.08)$ & $(0.33)$ \\
\hline
\end{tabular}

Table 6: Maximum likelihood estimates of intensity-model parameters with frailty for 5, 10, and 30 years of historical data 


\begin{tabular}{|l|c|c|c|}
\hline & 30 year & 10 year & 5 year \\
\hline \multirow{2}{*}{ constant } & -1.494 & -1.701 & -1.605 \\
& $(-16.65)$ & $(-5.57)$ & $(-3.30)$ \\
\hline \multirow{2}{*}{ distance to default } & -1.150 & -1.138 & -1.149 \\
& $(-36.79)$ & $(-17.73)$ & $(-12.10)$ \\
\hline \multirow{2}{*}{ trailing stock return } & -0.930 & -0.977 & -0.822 \\
& $(-6.76)$ & $(-3.49)$ & $(-1.89)$ \\
\hline \multirow{2}{*}{ 3-month T-bill rate } & -0.218 & -0.210 & -0.219 \\
& $(-9.47)$ & $(-3.01)$ & $(-2.12)$ \\
\hline \multirow{2}{*}{ trailing S\&P 500 return } & 0.907 & 0.277 & 0.440 \\
& $(3.51)$ & $(0.47)$ & $(0.48)$ \\
\hline
\end{tabular}

Table 7: Maximum likelihood estimates of intensity-model parameters without frailty for 5, 10 , and 30 years of historical data

\begin{tabular}{|l|c|c|c|c|c|c|}
\hline & $99.5 \%$ & $99 \%$ & $95 \%$ & $90 \%$ & $75 \%$ & $50 \%$ \\
\hline 5 year & $6.59 \%$ & $6.31 \%$ & $5.46 \%$ & $5.03 \%$ & $4.47 \%$ & $3.76 \%$ \\
\hline 10 year & $8.01 \%$ & $7.44 \%$ & $6.31 \%$ & $5.6 \%$ & $4.75 \%$ & $3.9 \%$ \\
\hline 30 year & $10.04 \%$ & $9.43 \%$ & $7.30 \%$ & $6.31 \%$ & $5.03 \%$ & $3.76 \%$ \\
\hline
\end{tabular}

Table 8: Quantiles of predicted number of defaults distribution data history comparison 


\begin{tabular}{|l|c|c|c|}
\hline & Bad State & Normal State & Good State \\
\hline \multirow{2}{*}{ constant } & $\begin{array}{c}-1.012 \\
(-15.13)\end{array}$ & $\begin{array}{l}-1.599 \\
(-13.19)\end{array}$ & $\begin{array}{l}-1.868 \\
(-5.87)\end{array}$ \\
\hline \multirow{2}{*}{ distance to default } & -1.180 & -1.146 & -1.214 \\
& $(-47.87)$ & $(-33.99)$ & $(-24.03)$ \\
\hline \multirow{2}{*}{ trailing stock return } & -0.717 & -0.942 & -0.856 \\
& $(-6.41)$ & $(-6.55)$ & $(-3.45)$ \\
\hline \multirow{2}{*}{ 3-month T-bill rate } & -0.426 & -0.221 & -0.142 \\
& $(-16.44)$ & $(-7.65)$ & $(-3.00)$ \\
\hline \multirow{2}{*}{ trailing S\&P 500 return } & 1.726 & 0.833 & 2.173 \\
& $(7.62)$ & $(3.08)$ & $(3.69)$ \\
\hline \multirow{2}{*}{ latent-factor volatility $\eta$} & 0.192 & 0.138 & 0.177 \\
& $(17.50)$ & $(7.47)$ & $(6.55)$ \\
\hline latent-factor mean re- & 0.021 & 0.025 & 0.025 \\
version $\kappa$ & $(6.96)$ & $(3.20)$ & $(3.23)$ \\
\hline
\end{tabular}

Table 9: Maximum likelihood estimates of intensity-model parameters with frailty for economic states comparison

\begin{tabular}{|l|c|c|c|c|c|c|}
\hline & $99.5 \%$ & $99 \%$ & $95 \%$ & $90 \%$ & $75 \%$ & $50 \%$ \\
\hline Good Economy & $4.5 \%$ & $4.1 \%$ & $3.0 \%$ & $2.6 \%$ & $1.9 \%$ & $1.3 \%$ \\
\hline Normal Economy & $10.04 \%$ & $9.43 \%$ & $7.30 \%$ & $6.31 \%$ & $5.03 \%$ & $3.76 \%$ \\
\hline Bad Economy & $32.0 \%$ & $29.3 \%$ & $22.5 \%$ & $19.3 \%$ & $14.7 \%$ & $10.6 \%$ \\
\hline
\end{tabular}

Table 10: Quantiles of predicted number of defaults distribution -economic states comparison 


\begin{tabular}{|l|c|c|c|c|}
\hline & $\geqslant 3 \%$ & $\geqslant 7 \%$ & $\geqslant 10 \%$ & $\geqslant 30 \%$ \\
\hline Good Economy & $5.0 \%$ & $0.018 \%$ & 0 & 0 \\
\hline Normal Economy & $5.66 \%$ & $0.59 \%$ & 0 & 0 \\
\hline Bad Economy & $99.2 \%$ & $79.2 \%$ & $53.5 \%$ & $0.72 \%$ \\
\hline
\end{tabular}

Table 11: Quantiles of predicted defaults distribution -economic states comparison

\begin{tabular}{|l|c|c|c|}
\hline & $\mathrm{S} / \mathrm{N} \mathrm{5}$ & $\mathrm{S} / \mathrm{N} \mathrm{10}$ & No Noise \\
\hline \multirow{2}{*}{ constant } & -1.710 & -1.658 & -1.599 \\
$(-22.24)$ & $(-22.30)$ & $(-13.19)$ \\
\hline \multirow{2}{*}{ distance to default } & -1.183 & -1.185 & -1.146 \\
& $(-37.23)$ & $(-37.46)$ & $(-33.99)$ \\
\hline \multirow{2}{*}{ trailing stock return } & -0.499 & -0.503 & -0.942 \\
& $(-3.74)$ & $(-3.73)$ & $(-6.55)$ \\
\hline \multirow{2}{*}{ 3-month T-bill rate } & -0.311 & -0.329 & -0.221 \\
& $(-13.87)$ & $(-14.75)$ & $(-7.65)$ \\
\hline \multirow{2}{*}{ trailing S\&P 500 return } & 1.959 & 2.020 & 0.833 \\
& $(5.50)$ & $(5.81)$ & $(3.08)$ \\
\hline \multirow{2}{*}{ latent-factor volatility $\eta$} & 0.158 & 0.160 & 0.138 \\
& $(9.03)$ & $(9.61)$ & $(7.47)$ \\
\hline latent-factor mean re- & 0.036 & 0.034 & 0.025 \\
version $\kappa$ & $(4.55)$ & $(4.69)$ & $(3.20)$ \\
\hline
\end{tabular}

Table 12: Data estimation error effect in 3 different scenarios, with (a) signal to noise ratio (S-to-N ratio) equals 10, (b) S-to-N ratio equals 5, (c) no noise.

\begin{tabular}{|l|l|l|l|}
\hline & $\geqslant 90 \%$ & $\geqslant 95 \%$ & $\geqslant 99 \%$ \\
\hline Original $(\$ 3.1 \mathrm{~B})$ & $28.4 \%$ & $30.9 \%$ & $35.8 \%$ \\
\hline Amended $(\$ 1.8 \mathrm{~B})$ & $20.0 \%$ & $23.6 \%$ & $27.2 \%$ \\
\hline Amended $(\$ 1.8 \mathrm{~B}) \mathrm{w} /$ frailty & $38.1 \%$ & $41.8 \%$ & $49.0 \%$ \\
\hline
\end{tabular}

Table 13: Predicted Default Distribution: application with a Lehman CDO (Freedom CCS 2008-1). 


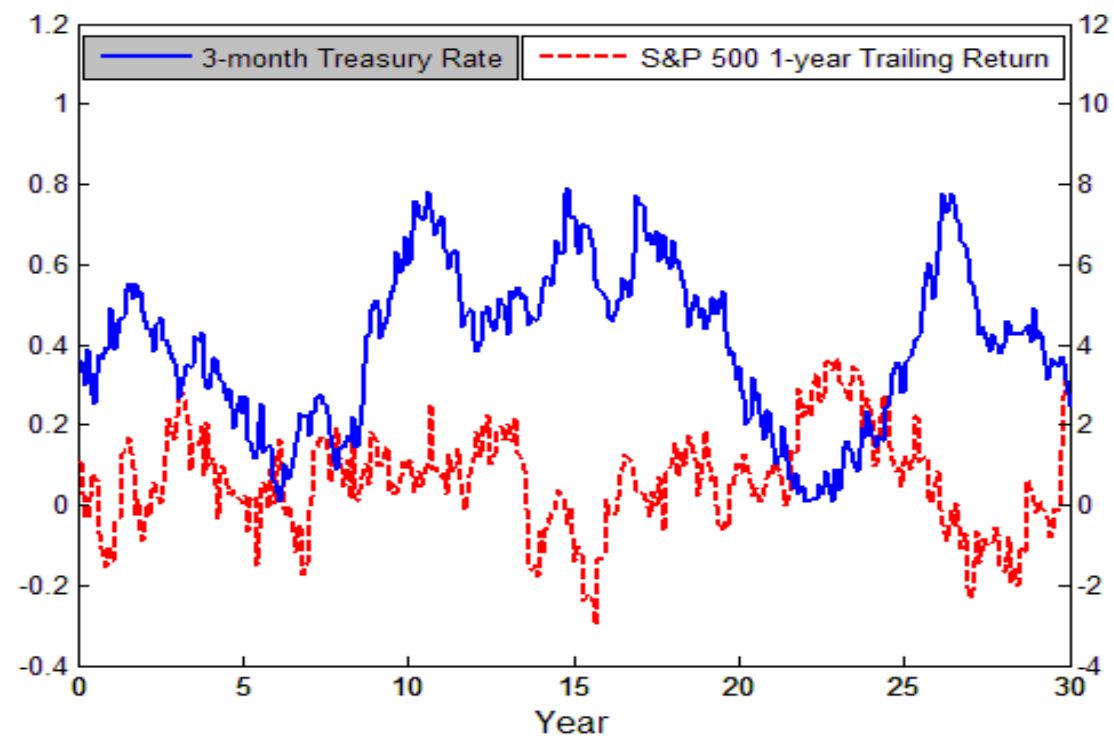

Figure 1: Simulated Treasury Rate and S\&P 500 Return for Validation Test. 


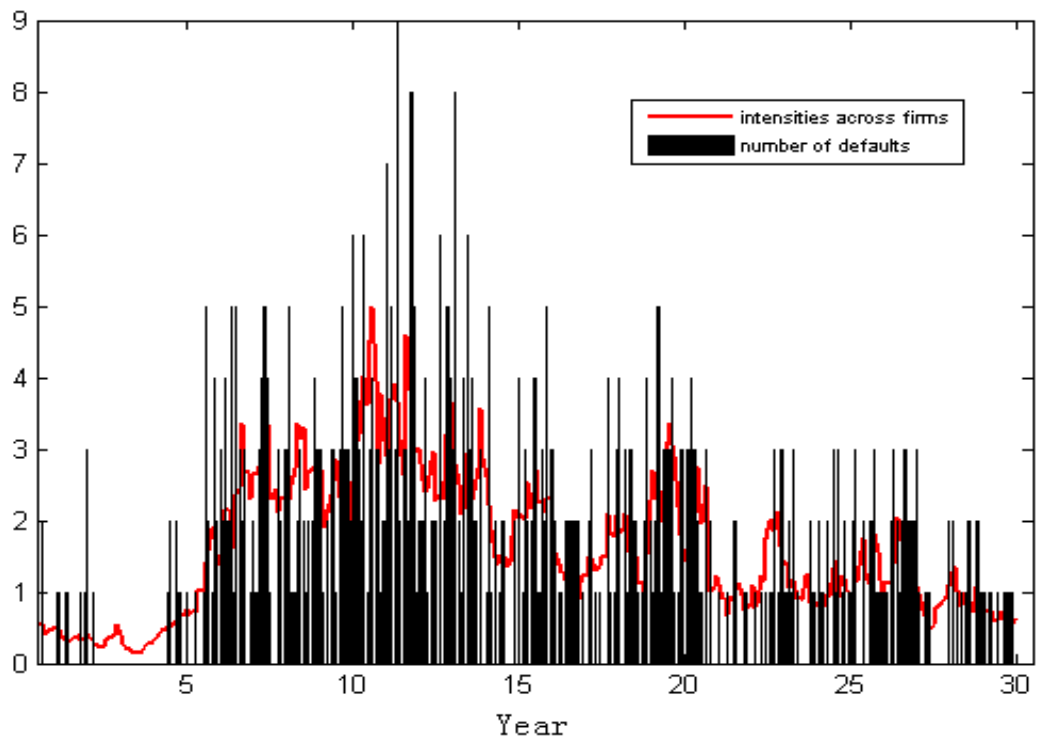

Figure 2: Intensity and defaults. The total across firms of estimated default intensities (line), and the number of defaults in each year (bar). 


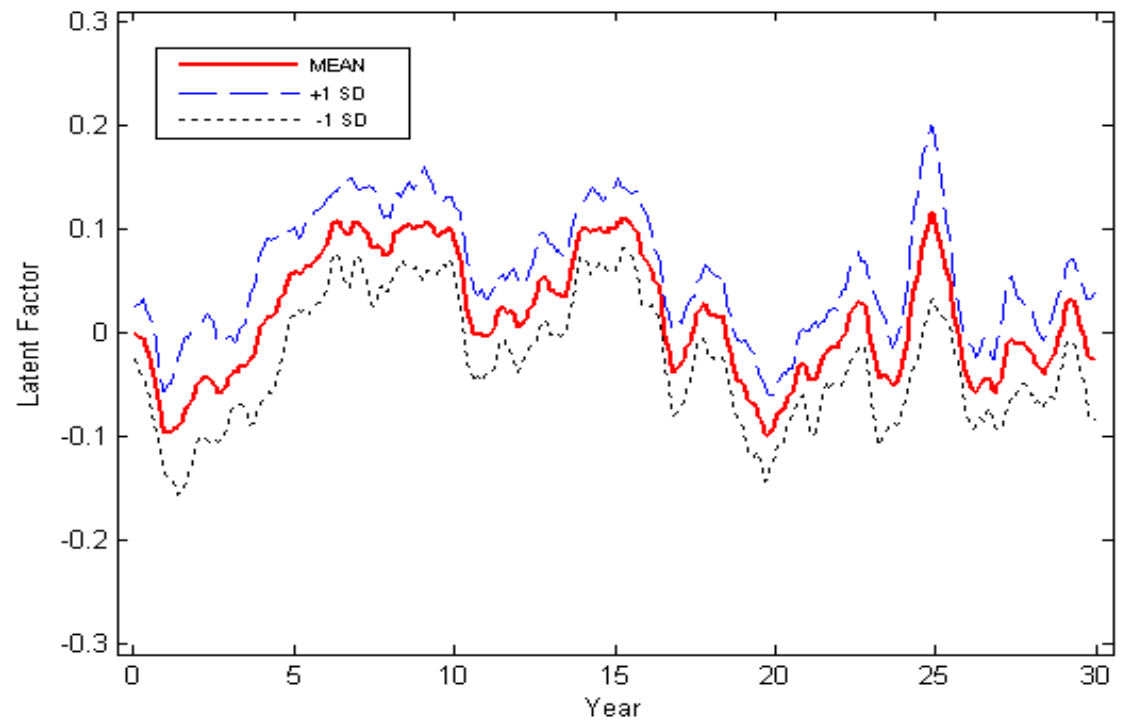

Figure 3: Latent without frailty. 


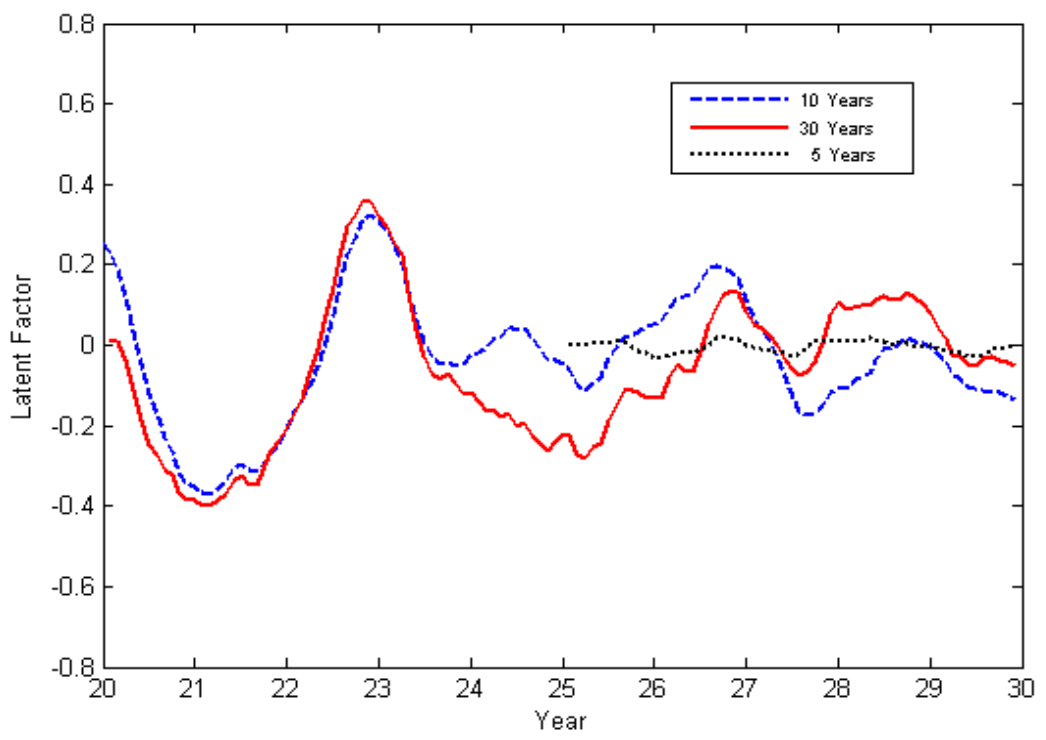

Figure 4: 5 years, 10 years and 30 years latent factor 


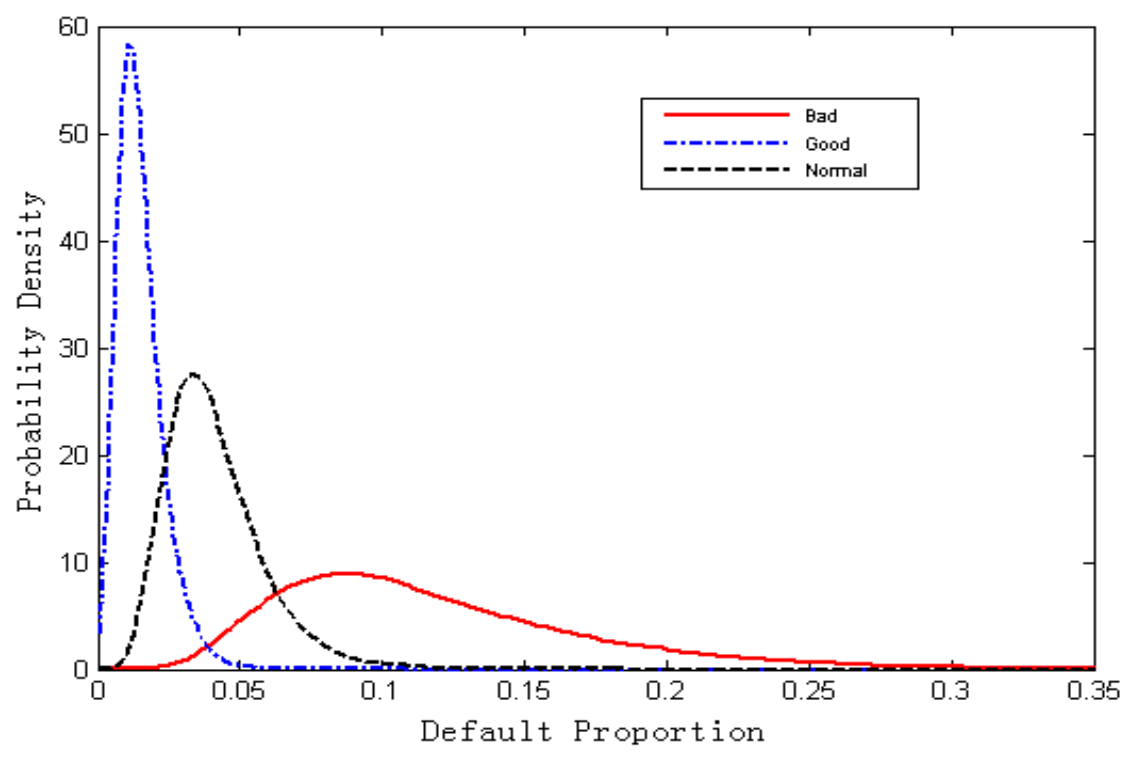

Figure 5: In year $30^{t h}$, the conditional probability density of the total number of defaults within five years with different economic states (a) Bad economic states, (b) Good economic states, and (c) Normal economic states. Gaussian kernel smoother with bandwidth 5 applied to a Monte-Carlo generated empirical distribution is used to generate the density estimates. 


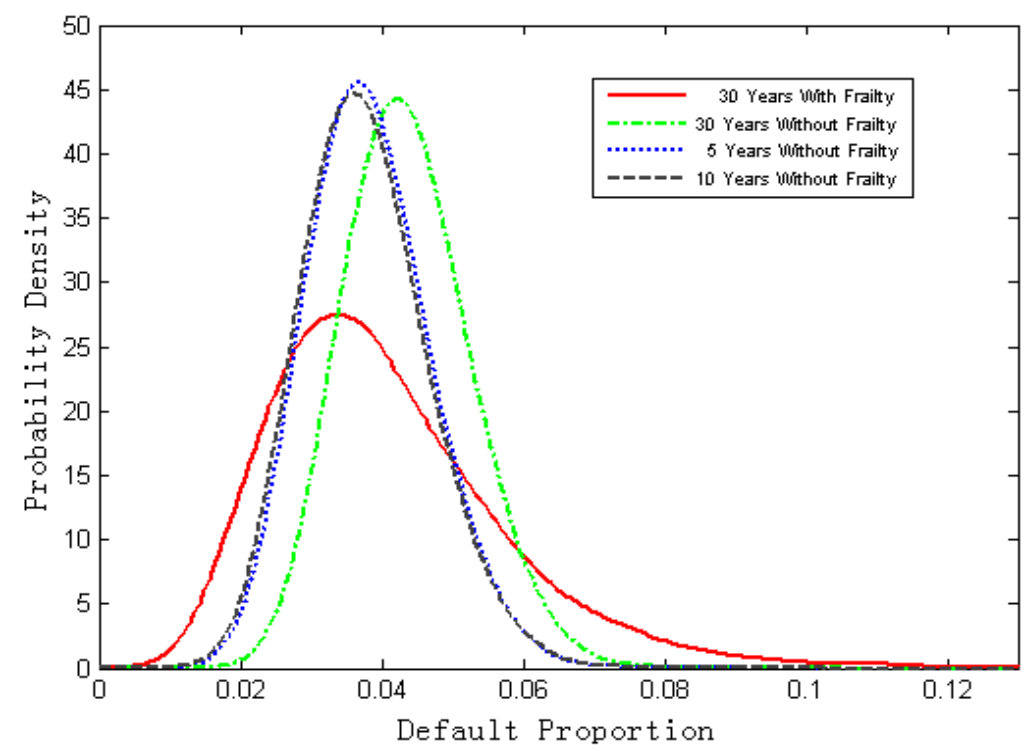

Figure 6: In year $30^{t h}$, the conditional probability density of the total number of defaults within five years with (a) 5 years data history in a model without frailty, (b) 10 years data history in a model with frailty, (c) 30 years data history in a model without frailty, and (d) 30 years data history in a model with frailty. Gaussian kernel smoother with bandwidth 5 applied to a Monte-Carlo generated empirical distribution is used to generate the density estimates. 


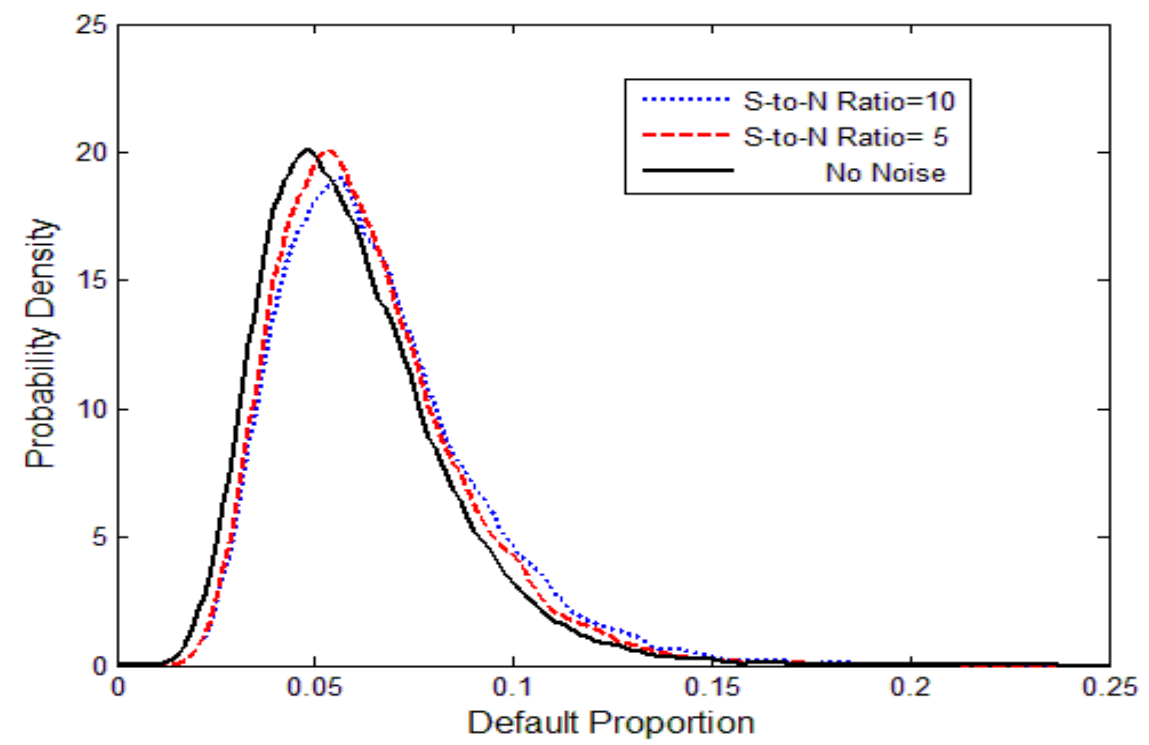

Figure 7: Data estimation error effect in 3 different scenarios, with (a) signal to noise ratio (S-to-N ratio) equals 10, (b) S-to-N ratio equals 5, (c) no noise.

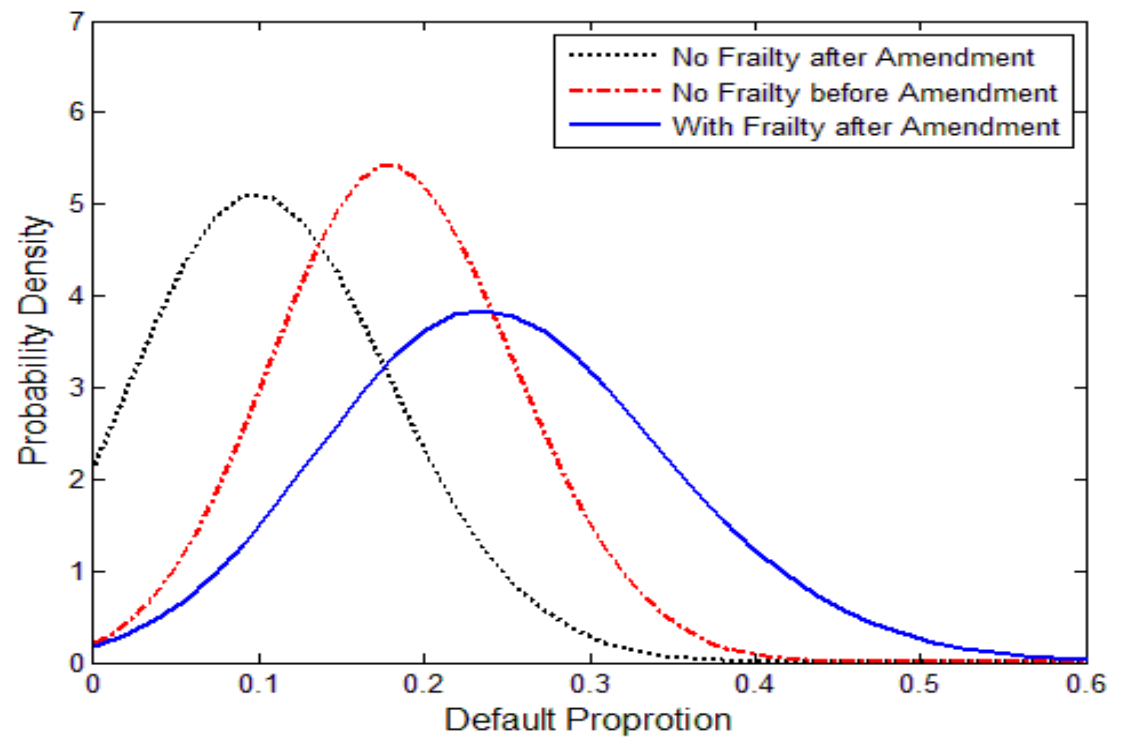

Figure 8: CDO rating outputs: application with a Lehman CDO (Freedom CCS 2008-1). 